\title{
Expression profile and clinical significance of Wnt signaling in human gliomas
}

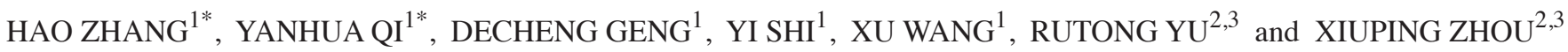 \\ ${ }^{1}$ The Graduate School; ${ }^{2}$ Institute of Nervous System Diseases, Xuzhou Medical University; \\ ${ }^{3}$ Brain Hospital, Affiliated Hospital of Xuzhou Medical University, Xuzhou, Jiangsu 221002, P.R. China
}

Received September 5, 2016; Accepted October 3, 2017

DOI: $10.3892 / \mathrm{ol} .2017 .7315$

\begin{abstract}
Wnt signaling has been identified as a critical regulator of human tumor development in vitro. However, there remains a lack of studies systematically examining the expression pattern and clinical relevance of the core molecules of Wnt signaling in glioma tissues. In the present study, it was identified that the mRNA expression levels of Wnt3a and 5a, and their receptors frizzled 2, 6 and 7 increased, whereas Wnt $7 \mathrm{~b}$ was markedly decreased in glioma relative to non-tumor tissue. The mRNA levels of $\beta$-catenin, adenomatous polyposis coli gene product, glycogen synthase kinase $3 \beta$ (GSK3 $\beta$ ) and AXIN1 and its target genes cyclin D1 and AXIN2 did not differ. Similarly, the protein levels of Wnt2b, 3a and 5a were increased in gliomas, while $\beta$-catenin, GSK $3 \beta$ and cyclin D1 were not. Furthermore, based on data from the R2: Genomics Analysis and Visualization Platform, the expression of Wnt $2 b$ and 5a, and frizzled 2, 6 and 7 were highly associated with the prognosis of patients with glioma. Taken together, the results of the present study demonstrate that $\beta$-catenin is not upregulated in gliomas and that the Wnt signaling pathway may promote glioma development via noncanonical or alternative pathways.
\end{abstract}

\section{Introduction}

Malignant glioma is the most frequent and aggressive type of primary brain tumor worldwide (1). According to the 2007 World Health Organization (WHO) classification, malignant

Correspondence to: Professor Xiuping Zhou, Institute of Nervous System Diseases, Xuzhou Medical University, 84 West Huai-hai Road, Xuzhou, Jiangsu 221002, P.R. China

E-mail:xpzhou@xzhmu.edu.cn

Professor Rutong Yu, Brain Hospital, Affiliated Hospital of Xuzhou Medical University, 99 West Huai-hai Road, Xuzhou, Jiangsu 221002, P.R. China

E-mail: yu.rutong@163.com

*Contributed equally

Key words: glioma, Wnt/ $\beta$-catenin, glycogen synthase kinase $3 \beta$, cyclin D1 gliomas are classified as grade II (diffuse astrocytoma), grade III (anaplastic astrocytoma) or grade IV (glioblastoma; GBM) (2,3). The mechanisms of glioma progression are heterogeneous, including the activation of oncogenes, the silencing of tumor suppressor genes and the development of glioma stem cells (4). Therefore, identifying genetic and molecular lesions underlying glioma progression is required in order to improve the current understanding of the precise mechanism underlying malignant glioma, and thus improve therapeutic methods.

Wnt pathway has widespread functions in a myriad of cell biological and developmental processes. There are $19 \mathrm{Wnt}$ ligands, and $>15$ receptors and co-receptors distributed in $>7$ protein families in mammals (5). Wnt molecules are secreted glycoproteins that regulate canonical or noncanonical signaling pathways $(6,7)$. In the canonical pathway, in the absence of Wnt ligands, cytoplasmic $\beta$-catenin is phosphorylated by a multiprotein destruction complex, which is composed of the scaffolding protein AXIN, glycogen synthase kinase 3 (GSK3), casein kinase 1 and the tumor suppressor, adenomatous polyposis coli (APC) gene product, resulting in $\beta$-catenin recognition by $\beta$-transducin repeat containing E3 ubiquitin protein ligase, an E3 ubiquitin ligase subunit. Subsequent to ubiquitination, $\beta$-catenin is degraded by the proteasome. Once bound by Wnt, the frizzled (FZD)/low-density lipoprotein receptor-related protein co-receptor complex activates the canonical signaling pathway, which inhibits $\beta$-catenin phosphorylation by sequestrating GSK3 into multivesicular compartments, thus leading to $\beta$-catenin stabilization and nucleus translocation to form a nuclear complex with the transcription factors T-cell factor (TCF)/lymphoid enhancer binding factor (LEF). Finally, the target genes of Wnt, including cyclin D1 and AXIN2, are transcribed to regulate cell proliferation and differentiation $(7,8)$.

At present, more than thirty years after the identification of Wnt molecules, the understanding of the complexity of the function of Wnt pathways in tumor initiation and progression has increased (9). Extensive studies, as reviewed in Zhang et al (10), have demonstrated that aberrant Wnt signaling serves a vital function in the progression of gliomas, including in cell proliferation, apoptosis, migration and invasion in vitro. Of these, the best understood is the Wnt canonical pathway, which contributes to tumorigenesis and cancer progression in a context-dependent manner. For example, different types of 
cancer are sensitive to different Wnt ligands, the stabilization of $\beta$-catenin and the activation of TCF/LEF family of transcription factors $(7,11)$. Analysis using The Cancer Genome Atlas (TCGA) database reveals that Wnt3 (12) and Wnt5a (13) are upregulated in human GBM. However, there remains a lack of studies focusing on the expression pattern of the core components of Wnt signaling in glioma tissues. In the present study, the expression of core Wnt signaling molecules at mRNA and protein levels were examined using a reverse transcription-quantitative polymerase chain reaction (RT-qPCR) and western blot analysis. Furthermore, the clinical implication of key Wnt signaling components was analyzed using data from the R2 Genomics Analysis and Visualization Platform.

\section{Materials and methods}

Tissue samples. Fresh glioma samples were collected from the Brain Hospital of the Affiliated Hospital of Xuzhou Medical University (Xuzhou, China) between February 2013 and May 2016. Surgically removed tissues were immediately stored in liquid nitrogen. The clinical stage of glioma was determined according to the 2007 WHO classification (2). There were 12 grade II cases, 11 grade III cases and 14 grade IV cases. A total of 11 non-tumorous brain tissue samples obtained from the internal decompression of patients with cerebral injuries were used as the control. Written informed consent was obtained from all patients prior to the study, and the present study was approved by the Research Ethics Committee of the Affiliated Hospital of Xuzhou Medical University.

Antibodies. The following monoclonal antibodies were used in the present study: Rabbit anti-Wnt2b (cat. no. ab178418; 1:1,000; Abcam, Cambridge, UK), rabbit monoclonal anti-GSK3 $\beta$ (cat. no. 9315S; 1:1,000; Cell Signaling Technology, Inc., Danvers, MA, USA), rabbit anti-GAPDH (cat. no. 2118S; 1:1,000; Cell Signaling Technology, Inc.), mouse anti-Wnt3a (cat. no. MAB1324; 1:250; R\&D Systems, Inc., Minneapolis, MN, USA), anti-Wnt5a (cat. no. MAB645; 1:250; R\&D Systems, Inc.), rabbit anti- $\beta$-catenin (cat. no. 9562S; $1: 1,000$; Cell Signaling Technology, Inc.) and mouse anti-cyclin D1 (cat. no. sc-450; 1:1,000, Santa Cruz Biotechnology, Inc., Dallas, TX, USA).

$R T$ - $q P C R$. Total RNA was extracted from tissue samples using TRIzol reagent (Invitrogen; Thermo Fisher Scientific, Inc., Waltham, MA, USA) and reverse-transcribed using a First-Strand cDNA kit (Roche Diagnostics, Indianapolis, IN, USA) to cDNA, according to the manufacturers' protocols. For qPCR, cDNA products were amplified using the FastStart Universal SYBR-Green Master (ROX; Roche Diagnostics) according to the manufacturer's protocol. The cycling conditions were as follows: $95^{\circ} \mathrm{C}$ for $10 \mathrm{~min}$, followed by 40 cycles of $95^{\circ} \mathrm{C}$ for $15 \mathrm{sec}$ and $60^{\circ} \mathrm{C}$ for $60 \mathrm{sec}$. The $2^{-\Delta \Delta \mathrm{Cq}}$ method was used to quantify gene expression (14). All values were normalized against the means of the non-tumorous group. All primers for the human samples are listed in Table I. $\beta$-catenin was designed by the authors of the present study, or obtained from previous studies, including Wnt2b, 3, 3a, 5a, 5b, 7b, 9, 11, FZD, 6, 7 and $\beta$-actin (15), GSK3 $\beta$ (16), APC, AXIN1, AXIN2 and cyclin D1 (17).
Western blot analysis. Protein lysates were extracted from non-tumorous and brain glioma tissues by using lysis buffer (containing $1 \mu \mathrm{M}$ pepstatin, $100 \mu \mathrm{M}$ leupeptin, $2 \mu \mathrm{g} / \mathrm{ml}$ aprotinin, $1 \mathrm{mM}$ dithiothreitol, $1 \mathrm{mM}$ benzamidine, $1 \mathrm{mM}$ $\mathrm{Na}_{3} \mathrm{VO}_{4}, 1 \mathrm{mM} \mathrm{NaF}$ and $200 \mu \mathrm{M}$ phenylmethylsulfonyl fluoride). Following incubation for $30 \mathrm{~min}$ on ice, cell lysates were centrifuged for $12,000 \mathrm{x} \mathrm{g}$ for $30 \mathrm{~min}$, at $4^{\circ} \mathrm{C}$. Protein lysates were measured using the Bicinchoninic Acid Protein Assay kit (Tiangen Biotech Co., Beijing, China) and an equal amount $(40 \mu \mathrm{g})$ of protein lysates were subjected to SDS-PAGE (10\% gel). Protein was transferred onto polyvinylidene difluoride membranes with a $0.45 \mu \mathrm{m}$ pore size (EMD Millipore, Billerica, MA, USA), which were blocked with $3 \%$ bovine serum albumin at room temperature for $2 \mathrm{~h}$ and probed with primary antibodies at $4^{\circ} \mathrm{C}$ overnight, and secondary antibodies [goat anti-rabbit immunoglobulin $\mathrm{G}$ (IgG)-horseradish peroxidase (HRP); cat. no. AP132P; 1:4,000; goat anti-mouse IgG-HRP; cat. no. AP124P; 1:4,000; both EMD Millipore] at room temperature for $2 \mathrm{~h}$. Bound antibodies were detected using the Pierce ECL Plus Western Blotting Substrate (Thermo Fisher Scientific, Inc.) and exposed to X-ray film. Band densities were quantified by using Image-Pro Plus Software (version 6.0; Media Cybernetics, Inc., Rockville, MD, USA) and the densitometric results were presented. All values were normalized to GAPDH expression.

Survival analysis. Survival analysis within the glioma dataset was performed using the glioma microarray dataset (Tumor Glioma French-284-MAS5.0-u133p2) from the R2: Genomics Analysis and Visualization Platform (http://r2.amc.nl). Kaplan-Meier analysis was conducted online, and P-values were calculated using the log-rank test. A cutoff method 'Kaplan scan' provided on the R2 platform was used to separate high and low expression groups of genes [Expression cutoff: Wnt2B (238512_at), 15.1; Wnt5A (205990_s_at), 133.3; FZD2 (210220_at), 58.3; FZD6 (203987_at), 50.6; FZD7 (203706_at), 249.2). These cutoff gene values belong to the high expression group. The Kaplan scan generates a Kaplan-Meier plot to illustrate the association between overall survival and a certain gene expression.

Statistical analysis. Results were presented as the mean \pm standard error of the mean. Statistical comparisons were performed using one-way analysis of variance, with post-hoc analysis performed using Dunnett's test. $\mathrm{P}<0.05$ was considered to indicate a statistically significant difference. Statistical analyses were performed using Microsoft Office Excel 2007 (Microsoft Corporation, Redmond, WA, USA), SPSS software (version 20.0; IBM Corp., Armonk, NY, USA) or GraphPad Prism (version 5; GraphPad Software Inc., La Jolla, CA, USA).

\section{Results}

Wnt signaling mRNA expression levels in glioma. Although the expression of $\mathrm{Wnt} / \beta$-catenin signaling pathway members in glioma has been demonstrated previously $(15,18-20)$, there is a lack of studies that have systematically investigated the expression of Wnt signaling. In order to comprehensively characterize the expression of Wnt signaling in glioma tissues, the R2: Genomics Analysis and Visualization Platform 
Table I. Primers used for quantitative polymerase chain reaction.

\begin{tabular}{|c|c|c|c|}
\hline Gene & Length, bp & Direction & Primer sequence \\
\hline \multirow[t]{2}{*}{ Wnt2b } & 102 & Forward & 5'-GCCGTGTCATGCTCAGAA-3' \\
\hline & & Reverse & 5'-GTGGACTACCCCTGCTGATG-3' \\
\hline \multirow[t]{2}{*}{ Wnt3 } & 104 & Forward & 5'-CTCGCTGGCTACCCAATTT-3' \\
\hline & & Reverse & 5'-GCCCAGAGATGTGTACTGCTG-3' \\
\hline \multirow[t]{2}{*}{ Wnt3a } & 218 & Forward & 5'-CATGAACCGCCACAACAAC-3' \\
\hline & & Reverse & 5'-TGGCACTTGCACTTGAGGT-3' \\
\hline \multirow[t]{2}{*}{ Wnt5a } & 200 & Forward & 5'-ATTGTACTGCAGGTGTACCTTAAAAC-3' \\
\hline & & Reverse & 5'-CССССТTATAAATGCAACTGTTC-3' \\
\hline \multirow[t]{2}{*}{ Wnt5b } & 175 & Forward & 5'-CTGCTGCTGCTGTTCACG-3' \\
\hline & & Reverse & 5'-CACCGGGTTCAAAGCTAATG-3' \\
\hline \multirow[t]{2}{*}{ Wnt7b } & 159 & Forward & 5'-CGCCTCATGAACCTGCATA-3' \\
\hline & & Reverse & 5'-GCTGCATCCGGTCCTCTA-3' \\
\hline \multirow[t]{2}{*}{ Wnt11 } & 137 & Forward & 5'-TGTGCTATGGCATCAAGTGG-3' \\
\hline & & Reverse & 5'-CAGTGTTGCGTCTGGTTCAG-3' \\
\hline \multirow[t]{2}{*}{$\beta$-actin } & 147 & Forward & 5'-CCAACCGCGAGAAGATGA-3' \\
\hline & & Reverse & 5'-CCAGAGGCGTACAGGGATAG-3' \\
\hline \multirow[t]{2}{*}{ FZD2 } & 157 & Forward & 5'-GGTGTCGGTGGCCTACAT-3' \\
\hline & & Reverse & 5'-GAGAAGCGCTCGTTGCAC-3' \\
\hline \multirow[t]{2}{*}{ FZD6 } & 201 & Forward & 5'-TGGGTTGGAAGCAAAAAGAC-3' \\
\hline & & Reverse & 5'-TCTTCGACTTTCACTGATTGGA-3' \\
\hline \multirow[t]{2}{*}{ FZD7 } & 210 & Forward & 5'-GCCAGCTTGTGCCTAATAGAA-3' \\
\hline & & Reverse & 5'-AGCCGGGAGAAACTCACAG-3' \\
\hline \multirow[t]{2}{*}{$\beta$-catenin } & 204 & Forward & 5'-CTTACACCCACCATCCCACT-3' \\
\hline & & Reverse & 5'-CCTCCACAAATTGCTGCTGT-3' \\
\hline \multirow[t]{2}{*}{ APC } & 209 & Forward & 5'-GCCCCTGACCAAAAAGGAAC-3' \\
\hline & & Reverse & 5'-TGGCAGCAACAGTCCCACTA-3' \\
\hline \multirow[t]{2}{*}{ GSK3 $\beta$} & 221 & Forward & 5'-CAAGCCAAACTTTGTGACTCAG-3' \\
\hline & & Reverse & 5'-TATCAGGATCCAGCAAGAGGTT-3' \\
\hline \multirow[t]{2}{*}{ Axin 1} & 130 & Forward & 5'-AGCCGTGTCGGACATGGA-3' \\
\hline & & Reverse & 5'-AAGTAGTACGCCACAACGATGCT-3' \\
\hline \multirow[t]{2}{*}{ Axin2 } & 210 & Forward & 5'-TGTGAGGTCCACGGAAACTG-3' \\
\hline & & Reverse & 5'-CGTCAGCGCATCACTGGATA-3' \\
\hline \multirow[t]{2}{*}{ Cyclin D1 } & 166 & Forward & 5'-TCAAATGTGTGCAGAAGGAGGT-3' \\
\hline & & Reverse & 5'-GACAGGAAGCGGTCCAGGTA-3' \\
\hline
\end{tabular}

APC, adenomatous polyposis coli; FZD, frizzled; GSK3 $\beta$, glycogen synthase kinase $3 \beta$.

database was interrogated, which revealed that, in patients with glioma, the median mRNA expression levels of Wnt $2 b$, Wnt5a, FZD1-7 were increased compared with other Wnt pathway members (Fig. 1). Thus, the mRNA expression levels of Wnt ligands, receptors, $\beta$-catenin destruction complex and its target genes cyclin D1 and AXIN2 were determined using qPCR. Based on previous studies, which detected the Wnt ligands in glioma cells and tissues $(15,18)$, eight members of the Wnt family (Wnt2b, 3, 3a, 5a, 5b, 7b, 9b and 11) were selected for further investigation. As presented in Fig. 2A, compared with non-tumor tissues, the mRNA expression level of Wnt3a and 5a in grade IV gliomas increased significantly, 4.57- and 5.40-fold, respectively. However, the mRNA expression level of Wnt7b in grade IV gliomas was significantly decreased, to $3 \%$ of that of non-tumor tissues (Fig. 2A). In addition, Wnt2b,
$3,5 \mathrm{~b}$ and 11 demonstrated no difference in mRNA expression levels between glioma and non-tumor tissue.

Furthermore, the mRNA expression levels of the Wnt receptors FZD2, 6 and 7 were detected, which serve critical functions in glioma $(10,15)$. The mRNA expression levels of FZD2 and FZD6 were significantly increased 4.90- and 5.61-fold in grade IV gliomas, respectively (Fig. 2A). Compared with non-tumor tissue, the mRNA expression level of FZD7 was significantly increased 5.35-fold in grade III gliomas (Fig. 2A). Furthermore, as presented in Fig. 2B, the mRNA expression level of the aforementioned molecules was presented as quartiles, which revealed that the median mRNA expression levels of Wnt3a, Wnt5a, FZD2, 6 and 7 were increased relative to the other molecules, which was similar to the results from the R2 platform and those of TCGA 


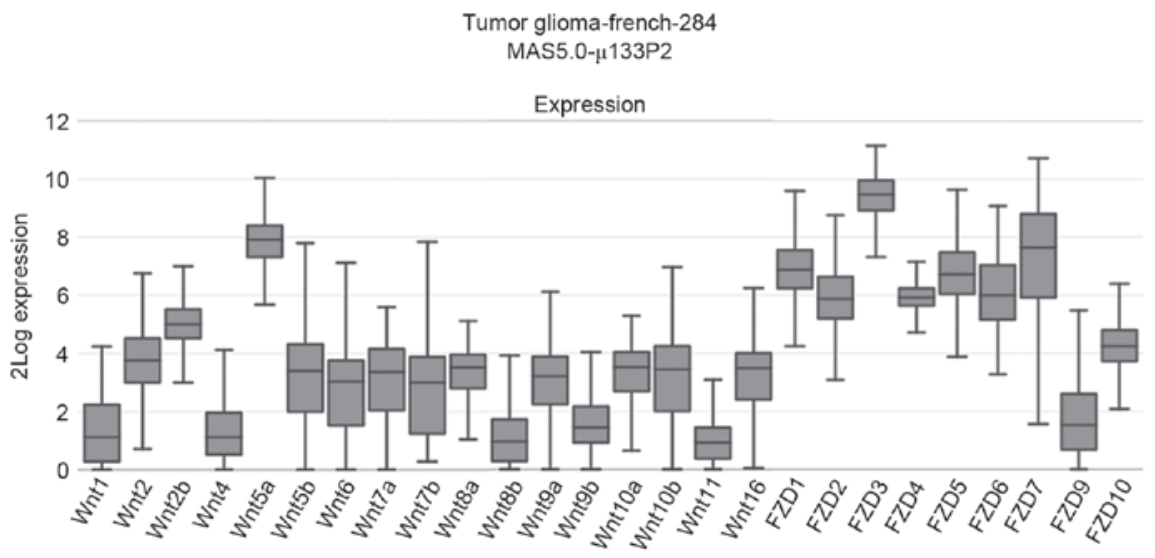

Figure 1. The relative mRNA expression level of a number of Wnt and FZD molecules in gliomas from the R2 French database ( $\mathrm{n}=284)$. Boxes represent the interquartile range; lines represent the location of the first quartile, median, and third quartile. FZD, frizzled.

A

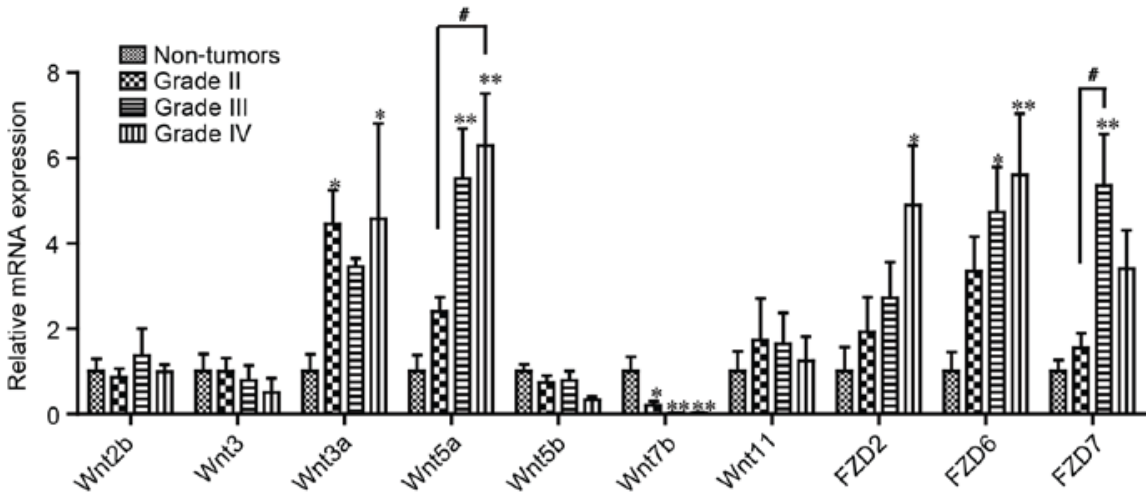

B

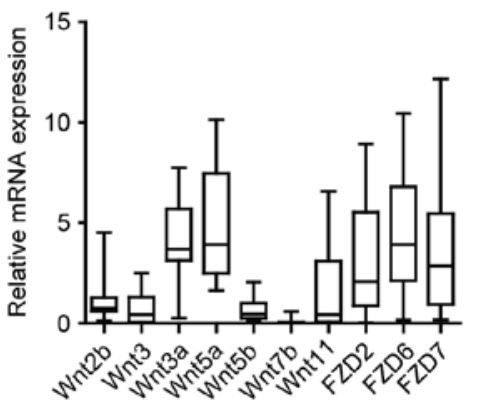

C

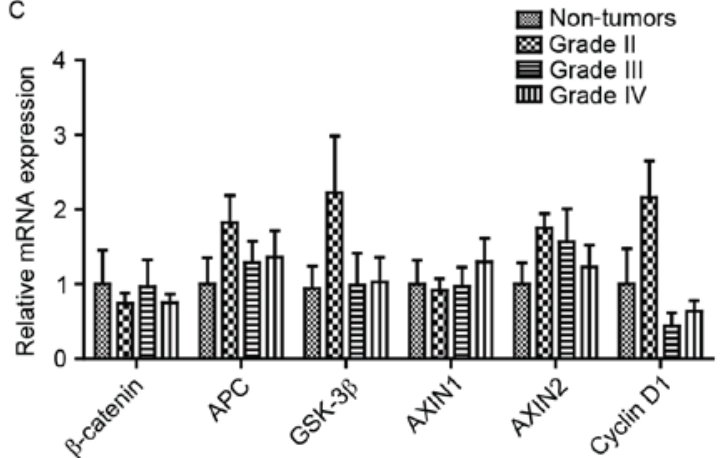

Figure 2. Wnt signaling mRNA expression levels in glioma tissue samples. mRNA expression levels of select Wnt and FZD molecules (A) between varying grades of glioma tissues and normal brain tissue, with results presented as mean \pm standard error of the mean, and (B) in glioma, presented as quartiles. (C) mRNA expression levels of $\beta$-catenin and its target genes in glioma tissues were quantified using quantitative polymerase chain reaction. Non-tumor brain tissue $(n=8)$, grade II glioma specimens $(n=8)$, grade III glioma specimens $(n=8)$ and grade IV glioma specimens $(n=8)$. mRNA expression levels were presented as the proportion of the mRNA expression levels in non-tumor brain tissues. ${ }^{*} \mathrm{P}<0.05,{ }^{* *} \mathrm{P}<0.01$ and ${ }^{* * * *} \mathrm{P}<0.001$ vs. non-tumor brain tissue; ${ }^{\#} \mathrm{P}<0.05$ as indicated. FZD, frizzled; GSK-3 $\beta$, glycogen synthase kinase- $3 \beta$.

database (13). However, significant changes were not detected in the mRNA expression levels of $\beta$-catenin and its degradation complex, including APC, GSK $3 \beta$, AXIN1, cyclin D1 or AXIN2, in the glioma samples (Fig. 2C).

Wnt signaling pathway protein expression levels in glioma. The protein expression levels of a number of the core components of Wnt signaling were analyzed; it was revealed that Wnt $2 b$, $3 \mathrm{a}$ and $5 \mathrm{a}$ expression levels were significantly increased, 2.49-, 3.86- and 3.08-fold in grade IV gliomas, respectively, compared with non-tumor brain tissue (Fig. 3A and B). However, no significant difference in the protein expression levels of $\beta$-catenin, GSK3 $\beta$ and cyclin D1 were observed in glioma tissue compared with non-tumor brain tissue (Fig. 3B).

Using data from the R2: Genomics Analysis and Visualization Platform, the association between the clinical outcome of patients with glioma and the expression of Wnt molecules was analyzed using a log-rank test. During the follow-up period, patients with the high expression of Wnt $2 \mathrm{~b}$ had significantly reduced survival times compared with 
A

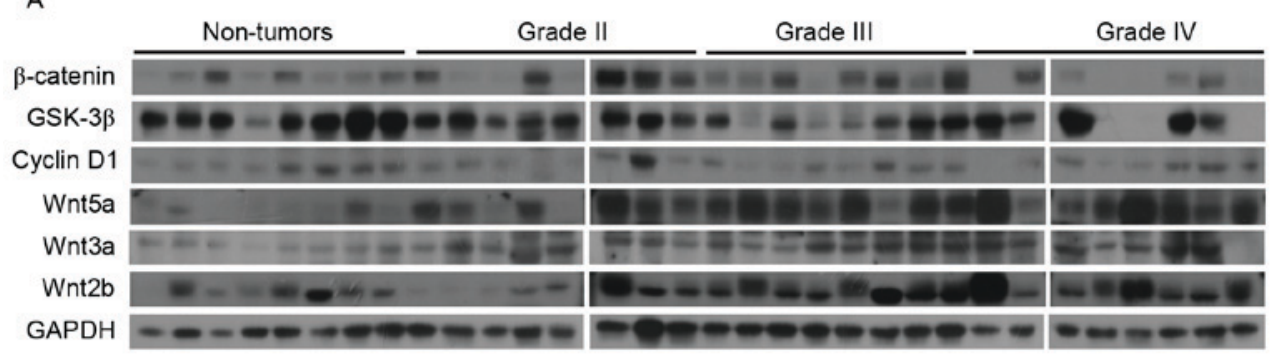

B

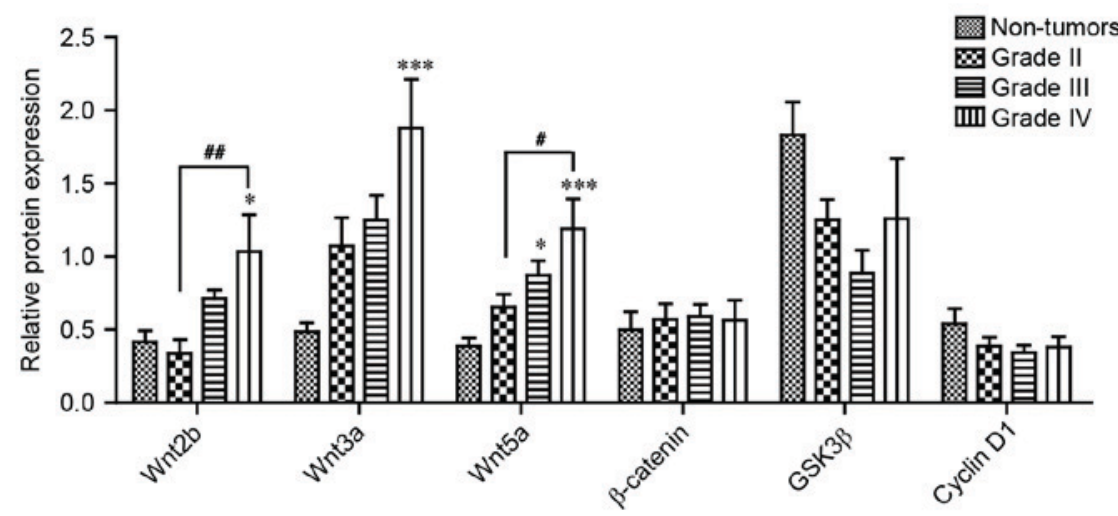

Figure 3. Wnt signaling protein expression level in glioma tissue samples. The protein expression levels of Wnt molecules in non-tumor and glioma tissue were analyzed using (A) western blot analysis that was then (B) quantified. Non-tumor brain tissues ( $\mathrm{n}=11,8$ cases presented), grade II glioma specimens ( $\mathrm{n}=12$, 8 cases presented), grade III glioma specimens ( $n=11,8$ cases presented) and grade IV glioma specimens ( $n=14,8$ cases presented) were included. Relative protein expression levels were expressed as the proportion of the total protein levels in non-tumor brain tissues. Results are presented as mean \pm standard error of the mean. ${ }^{*} \mathrm{P}<0.05,{ }^{* *} \mathrm{P}<0.01$ and ${ }^{* * *} \mathrm{P}<0.001$ vs. non-tumor brain tissue; ${ }^{*} \mathrm{P}<0.05$ and ${ }^{\# \#} \mathrm{P}<0.01$ as indicated. GSK3 $\beta$, glycogen synthase kinase $3 \beta$.
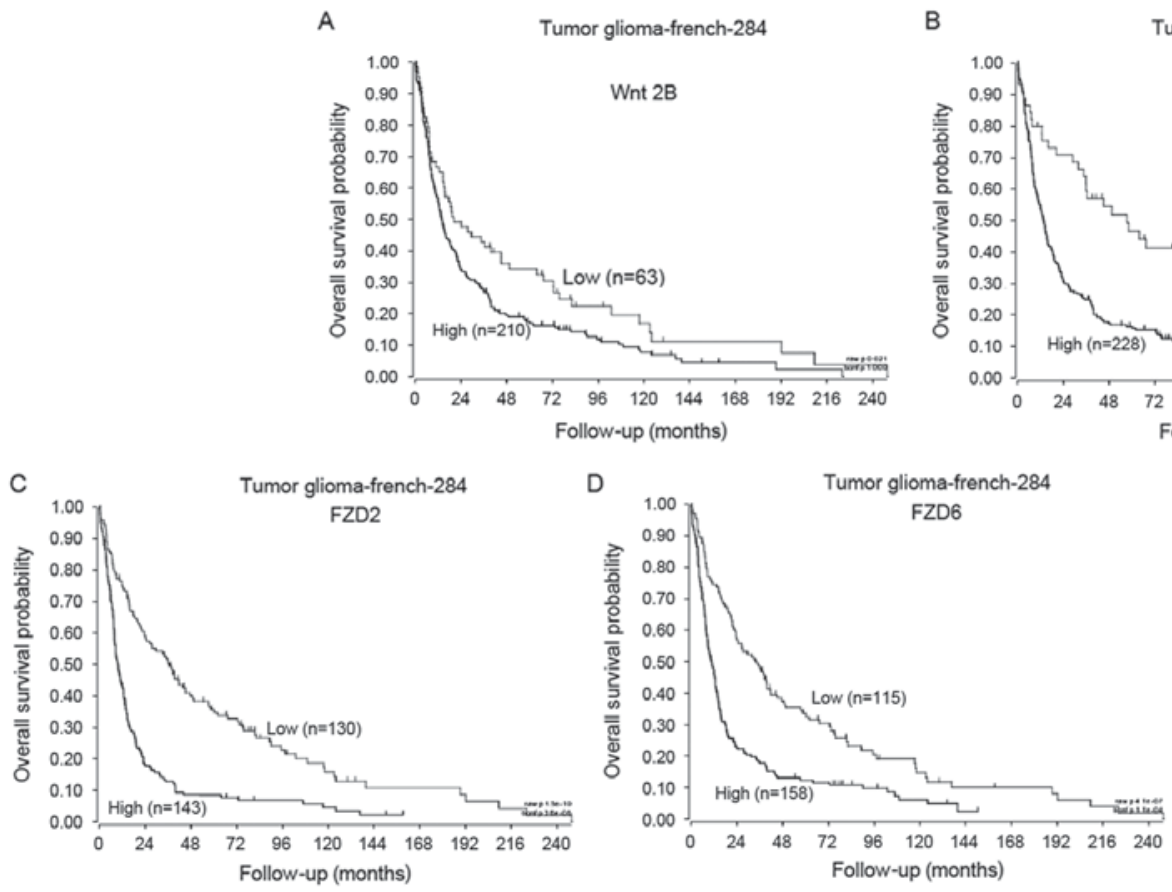
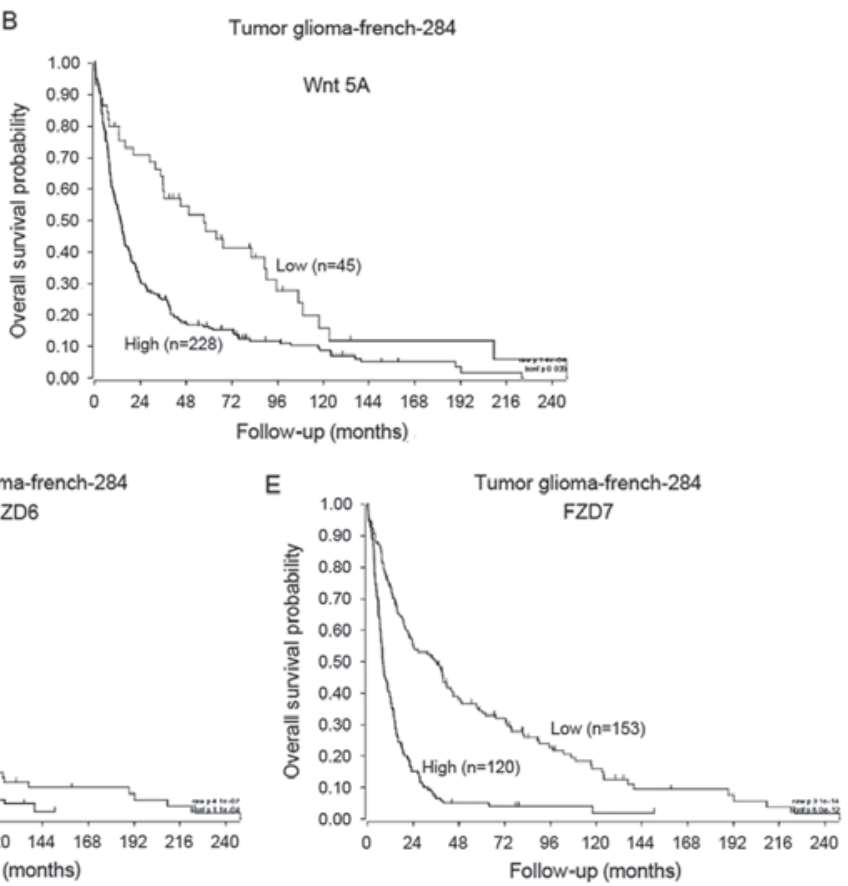

Figure 4. Prognostic evaluation of the core Wnt signaling molecules. Association between high and low expression patterns of (A) Wnt2B, (B) Wnt5A, (C) FZD2, (D) FZD 6 and (E) FZD 7 and overall survival time based on the R2 database, presented by Kaplan-Meier plots. FZD, frizzled.

patients with low expression (Fig. 4A; Wnt2b high, $\mathrm{n}=210$, Wnt2b low, $\mathrm{n}=63$; $\mathrm{P}<0.05)$. Similarly, patients with low Wnt5a expression had a significantly longer overall survival than those with high Wnt5a expression (Fig. 4B; Wnt5a high, $\mathrm{n}=228$, Wnt5a low, $\mathrm{n}=45 ; \mathrm{P}<0.01)$. Additionally, the overall survival rates for patients with the high expression of FZD2, 6 or 7 was significantly reduced than those with low FZD2, 6 and 7 expression (Fig. 4C-E; FZD2 high, n=143, FZD2 low, 
n=130; FZD6 high, n=158, FZD6 low, n=115; FZD7 high, $\mathrm{n}=120$, FZD7 low, $\mathrm{n}=135 ; \mathrm{P}<0.01$ ).

\section{Discussion}

Accumulating studies have demonstrated that Wnt/ $\beta$-catenin signaling components are aberrantly expressed in numerous types of human tumor, which contribute to tumor initiation and development (9). In the present study, it was revealed that the mRNA expression levels of Wnt3a, 5a and the receptors FZD2, 6 and 7 were upregulated, whereas Wnt7b was decreased. However, no significant changes were observed in $\beta$-catenin, APC, AXIN1/2, GSK3 $\beta$, and cyclin D1 mRNA expression levels. Similarly, at the protein level, the expression levels of Wnt2b, $3 \mathrm{a}$ and $5 \mathrm{a}$ increased, whereas those of $\beta$-catenin, GSK $3 \beta$ and cyclin D1 did not exhibit any changes.

Known as the classical canonical Wnt molecules, Wnt2, 2b, $3 \mathrm{a}$ and $7 \mathrm{~b}$ have been widely detected in various types of cancer, including esophageal cancer (21), glioblastoma (12) and prostate cancer (22). Specifically, Wnt2 secreted by tumor fibroblast promotes the translocation of $\beta$-catenin, which contributes to cell motility and invasiveness in esophageal cancer (21). $\mathrm{Pu}$ et al (18) revealed that the mRNA expression of Wnt2 was increased in gliomas. Additionally, anti-Wnt2 monoclonal antibodies induced apoptosis in the treatment of non-small cell lung cancer (NSCLC) (23), melanoma (24) and mesothelioma cells (25). Wnt2b, a known homolog of Wnt2 (26), has rarely been studied in glioma. In 2012, Liu et al (27) reported that Wnt2b was upregulated in gastric cancer, hepatocellular carcinoma and NSCLC, which was demonstrated to be negatively associated with the prognosis of patients with NSCLC. The study also identified that Wnt $2 \mathrm{~b}$ may promote the expression of c-Myc and survivin via canonical signaling pathways. Wnt7b, identified as a direct target gene of androgen receptors, is markedly upregulated in castration-resistant prostate cancer cells (22). Transcriptional profiling also revealed an increased expression of Wnt $7 \mathrm{~b}$ in pancreatic adenocarcinoma cell lines (28). TCGA database analysis previously revealed that 52/53 human breast cancer cell lines demonstrated the substantial upregulation of Wnt7b (29). Kaur et al (12) reported that Wnt3a was upregulated in glioma cells, primary cultures and glioma stem cells in addition to tumor tissues, whereas further TCGA database analysis revealed the high expression of Wnt 3 in $55 \%$ of all glioblastoma samples.

Regarding $\beta$-catenin, Liu et al (19) and Shi et al (20) demonstrated that mRNA and protein levels increased with an increase in astrocytic glioma pathological grade. In contrast, $\mathrm{Pu}$ et al (18) reported that the mRNA expression of $\beta$-catenin in gliomas analyzed using RT-qPCR did not exhibit any change, which is consistent with the results of the present study. This previous study additionally reported that the protein level of $\beta$-catenin was significantly higher in grade III and IV gliomas compared with grade I and II gliomas, as assessed by immunohistochemistry, and was implicated in cell proliferation and glioma growth. However, in the present study, from the western blot analysis of 37 glioma and 11 non-tumor brain tissues, it was revealed that $\beta$-catenin protein levels varied between different glioma grades, whereas no significant change was observed between non-tumor tissues and glioma samples. It is reported that the Wnt receptors FZD2, 6 and 7 are upregulated in human malignant glioma cell lines (15). However, Salsano et al (30) identified that although FZD2 is overexpressed in medulloblastomas, FZD7 is underexpressed in certain cases of the medulloblastomas. In the present study, it was revealed that these Wnt receptors were also overexpressed in glioma tissue, indicating that they may serve functions in glioma progression. As for why the mRNA expression of FZD7 was higher in grade III gliomas compared with non-tumor tissues, while grade IV gliomas did not exhibit any difference, this may be due to one of the following reasons: Firstly, only 8 samples of each grade were used in the present study for qPCR analysis. The lack of variation caused by the limited number of samples may result in no significant differences between non-tumor tissues and grade IV glioma tissue being identified. Secondly, it has been reported that a number of molecules exhibit expression differences in different glioma cell types. However, in the present study, samples were selected only according to the WHO grade and not the cell type, which may be the cause of this difference.

Wnt5a, one of the most highly investigated non-canonical Wnt molecules, has been revealed to be upregulated in multiple types of cancer, including melanoma (31), breast carcinoma (32), pancreatic cancer (33), prostate carcinoma (34) and human glioblastoma (13). Notably, Wnt5a is the most upregulated Wnt member in glioma cells and tissues, which promotes cell proliferation, migration and tumorigenesis both in vitro and in vivo $(15,35)$. In addition, Wnt5a is associated with the antagonization of the canonical Wnt/ $\beta$-catenin activity in mammalian cells and Xenopus embryos (36-38). Topol et al (39) subsequently uncovered that Wnt5a inhibited canonical Wnt/ $\beta$-catenin signaling by modulating $\beta$-catenin degradation via a GSK3-independent mechanism. Similar inhibition mechanisms of Wnt5a have been identified in hematopoietic stem cells (40), hepatocyte proliferation (41), dermal papilla cells and non-melanoma skin cancer (42). Therefore, Wnt5a functions as an antagonist of the canonical Wnt/ $/$-catenin pathway, and may account for the unusual results in the present study concerning Wnt $/ \beta$-catenin signaling in gliomas.

It has been reported that key components of the Wnt pathway affect the survival of patients, including effects on metastasis, chemoresistance and cell proliferation. For example, the upregulation of Wnt5a may enhance, whilst the downregulation may reduce, the proliferation and tumorigenesis of GBM-05 and U87MG cell lines (35). The knockdown of Wnt5a suppresses the migration, invasion and infiltrative capacity of glioma cells primarily via a matrix metallopeptidase-2-dependent mechanism (15). It was revealed that FZD2 expression enhances epithelial to mesenchymal transition, and cell migration and invasion through FYN proto-oncogene, Src family tyrosine kinase and signal transducer and activator of transcription 3. Specific antibody targeting of FZD2 may decrease tumor development and metastasis in xenograft mouse models of colorectal carcinoma (43). In the circulating tumor cells (CTCs) of pancreatic carcinoma, the expression of Wnt2 may promote anchorage-independent sphere formation and metastatic ability (44). Additionally, the $\beta$-catenin-independent Wnt pathway has been demonstrated to be upregulated in the CTCs of prostate carcinoma cell lines that demonstrate 
resistance to androgen receptor inhibition (45). In summary, increasing evidence has revealed that $\beta$-catenin-dependent and -independent Wnt signaling may promote tumorigenesis in a tissue-specific manner (46). Furthermore, the proliferation of glioma cells may be inhibited by targeting specific molecules using Wnt 2 and $\beta$-catenin small interfering RNAs $(18,47,48)$. $\beta$-catenin expression demonstrates an association with the poor prognosis of patients with GBM, including shorter survival times $(19,49)$. The aforementioned previous studies are in line with the data presented in the R2 Platform, in which patients with a high expression of Wnt5a, Wnt2b, FZD2, FZD6 and FZD7 exhibited a worse overall survival time.

In the present study, only western blot and RT-qPCR analyses were used to illustrate the expression of Wnt ligands, the Wnt/ $\beta$-catenin pathway and its target genes in the context of gliomas. The results of the present study clearly indicate that $\beta$-catenin is not upregulated in gliomas, and Wnt molecules may serve important functions in glioma progression via the noncanonical pathway. Another potential explanation is that the effect of the Wnt/ $\beta$-catenin canonical signaling on glioma is antagonized by Wnt5a upregulation. Thus, future studies should aim to explain the effect of Wnt/ $\beta$-catenin on glioma cells in vitro. Furthermore, the results of the present study offer a potential opportunity to further explore the precise function of Wnt $2 b$ and Wnt7b in the context of gliomas.

\section{Acknowledgements}

The present study was supported by the National Natural Science Foundation of China (grant nos., 81372699 and 81472345), the 333 Talent Project of the Jiangsu Province (grant no. BRA2015394) and the Six Major Talent Summit of the Jiangsu Province (grant no. WSW-039).

\section{References}

1. Louis DN, Perry A, Reifenberger G, von Deimling A, Figarella-Branger D, Cavenee WK, Ohgaki H, Wiestler OD, Kleihues P and Ellison DW: The 2016 World Health Organization Classification of Tumors of the Central Nervous System: A summary. Acta Neuropathol 131: 803-820, 2016.

2. Wen PY and Kesari S: Malignant gliomas in adults. N Engl J Med 359: 492-507, 2008

3. Louis DN, Ohgaki H, Wiestler OD, Cavenee WK, Burger PC, Jouvet A, Scheithauer BW and Kleihues P: The 2007 WHO classification of tumours of the central nervous system. Acta Neuropathol 114: 97-109, 2007.

4. Van Meir EG, Hadjipanayis CG, Norden AD, Shu HK, Wen PY and Olson JJ: Exciting new advances in neuro-oncology: The avenue to a cure for malignant glioma. CA Cancer J Clin 60: $166-193,2010$

5. Willert K and Nusse R: Wnt proteins. Cold Spring Harb Perspect Biol 4: a007864, 2012.

6. Yu J and Virshup DM: Updating the Wnt pathways. Biosci Rep 34: pii: e00142, 2014.

7. MacDonald BT, Tamai K and He X: Wnt/beta-catenin signaling: Components, mechanisms, and diseases. Dev Cell 17: 9-26, 2009.

8. Baarsma HA, Königshoff M and Gosens R: The WNT signaling pathway from ligand secretion to gene transcription: Molecular mechanisms and pharmacological targets. Pharmacol Ther 138: 66-83, 2013.

9. Polakis P: Wnt signaling in cancer. Cold Spring Harb Perspect Biol 4: pii: a008052, 2012.

10. Zhang K, Zhang J, Han L, Pu P and Kang C: Wnt/beta-catenin signaling in glioma. J Neuroimmune Pharmacol 7: 740-749, 2012.

11. Anastas JN and Moon RT: WNT signalling pathways as therapeutic targets in cancer. Nat Rev Cancer 13: 11-26, 2013.
12. Kaur N, Chettiar S, Rathod S, Rath P, Muzumdar D, Shaikh ML and Shiras A: Wnt3a mediated activation of Wnt $/ \beta$-catenin signaling promotes tumor progression in glioblastoma. Mol Cell Neurosci 54: 44-57, 2013.

13. Reis M, Czupalla CJ, Ziegler N, Devraj K, Zinke J, Seidel S, Heck R, Thom S, Macas J, Bockamp E, et al: Endothelial Wnt $/ \beta$-catenin signaling inhibits glioma angiogenesis and normalizes tumor blood vessels by inducing PDGF-B expression. J Exp Med 209: 1611-1627, 2012.

14. Livak KJ and Schmittgen TD: Analysis of relative gene expression data using real-time quantitative PCR and the 2(-Delta Delta C(T)) method. Methods 25: 402-408, 2001.

15. Kamino M, Kishida M, Kibe T, Ikoma K, Iijima M, Hirano H, Tokudome M, Chen L, Koriyama C, Yamada K, et al: Wnt-5a signaling is correlated with infiltrative activity in human glioma by inducing cellular migration and MMP-2. Cancer Sci 102: 540-548, 2011.

16. Klein D, Demory A, Peyre F, Kroll J, Augustin HG, Helfrich W, Kzhyshkowska J, Schledzewski K, Arnold B and Goerdt S: Wnt2 acts as a cell type-specific, autocrine growth factor in rat hepatic sinusoidal endothelial cells cross-stimulating the VEGF pathway. Hepatology 47: 1018-1031, 2008.

17. Azzolin L, Zanconato F, Bresolin S, Forcato M, Basso G, Bicciato S, Cordenonsi M and Piccolo S: Role of TAZ as mediator of Wnt signaling. Cell 151: 1443-1456, 2012.

18. Pu P, Zhang Z, Kang C, Jiang R, Jia Z, Wang G and Jiang $\mathrm{H}$ : Downregulation of Wnt2 and beta-catenin by siRNA suppresses malignant glioma cell growth. Cancer Gene Ther 16: 351-361, 2009.

19. Liu X, Wang L, Zhao S, Ji X, Luo Y and Ling F: $\beta$-Catenin overexpression in malignant glioma and its role in proliferation and apoptosis in glioblastma cells. Med Oncol 28: 608-614, 2011.

20. Shi Z, Qian X, Li L, Zhang J, Zhu S, Zhu J, Chen L, Zhang K, Han L, $\mathrm{Yu}$ S, et al: Nuclear translocation of $\beta$-catenin is essential for glioma cell survival. J Neuroimmune Pharmacol 7: 892-903, 2012.

21. Fu L, Zhang C, Zhang LY, Dong SS, Lu LH, Chen J, Dai Y, Li Y, Kong KL, Kwong DL and Guan XY: Wnt2 secreted by tumour fibroblasts promotes tumour progression in oesophageal cancer by activation of the Wnt/ $\beta$-catenin signalling pathway. Gut 60 : 1635-1643, 2011.

22. Zheng D, Decker KF, Zhou T, Chen J, Qi Z, Jacobs K, Weilbaecher KN, Corey E, Long F and Jia L: Role of WNT7B-induced noncanonical pathway in advanced prostate cancer. Mol Cancer Res 11: 482-493, 2013.

23. You L, He B, Xu Z, Uematsu K, Mazieres J, Mikami I, Reguart N, Moody TW, Kitajewski J, McCormick F and Jablons DM: Inhibition of Wnt-2-mediated signaling induces programmed cell death in non-small-cell lung cancer cells. Oncogene 23: 6170-6174, 2004.

24. Mazieres J, You L, He B, Xu Z, Twogood S, Lee AY, Reguart N, Batra S, Mikami I and Jablons DM: Wnt2 as a new therapeutic target in malignant pleural mesothelioma. Int J Cancer 117: 326-332, 2005.

25. You L, He B, Xu Z, Uematsu K, Mazieres J, Fujii N, Mikami I, Reguart N, McIntosh JK, Kashani-Sabet M, et al: An anti-Wnt-2 monoclonal antibody induces apoptosis in malignant melanoma cells and inhibits tumor growth. Cancer Res 64: 5385-5389, 2004.

26. Katoh M: WNT2B: Comparative integromics and clinical applications (Review). Int J Mol Med 16: 1103-1108, 2005.

27. Liu D, Kadota K, Ueno M, Nakashima N, Yokomise H and Huang $\mathrm{Cl}$ : Adenoviral vector expressing short hairpin RNA targeting Wnt2B has an effective antitumour activity against Wnt2B2-overexpressing tumours. Eur J Cancer 48: 1208-1218, 2012.

28. Arensman MD, Kovochich AN, Kulikauskas RM, Lay AR, Yang PT, Li X, Donahue T, Major MB, Moon RT, Chien AJ and Dawson DW: WNT7B mediates autocrine Wnt/ $\beta$-catenin signaling and anchorage-independent growth in pancreatic adenocarcinoma. Oncogene 33: 899-908, 2014.

29. Yeo EJ, Cassetta L, Qian BZ, Lewkowich I, Li JF, Stefater JA III, Smith AN, Wiechmann LS, Wang Y, Pollard JW and Lang RA: Myeloid WNT7b mediates the angiogenic switch and metastasis in breast cancer. Cancer Res 74: 2962-2973, 2014.

30. Salsano E, Paterra R, Figus M, Menghi F, Maderna E, Pollo B, Solero CL, Massimi L and Finocchiaro G: Expression profile of frizzled receptors in human medulloblastomas. J Neurooncol 106: 271-280, 2012

31. Da Forno PD, Pringle JH, Hutchinson P, Osborn J, Huang Q, Potter L, Hancox RA, Fletcher A and Saldanha GS: WNT5A expression increases during melanoma progression and correlates with outcome. Clin Cancer Res 14: 5825-5832, 2008. 
32. Fernandez-Cobo M, Zammarchi F, Mandeli J, Holland JF and Pogo BG: Expression of Wnt5A and Wnt10B in non-immortalized breast cancer cells. Oncol Rep 17: 903-907, 2007.

33. Ripka S, König A, Buchholz M, Wagner M, Sipos B, Klöppel G, Downward J, Gress T and Michl P: WNT5A-target of CUTL1 and potent modulator of tumor cell migration and invasion in pancreatic cancer. Carcinogenesis 28: 1178-1187, 2007.

34. Wang Q, Williamson M, Bott S, Brookman-Amissah N, Freeman A, Nariculam J, Hubank MJ, Ahmed A and Masters JR: Hypomethylation of WNT5A, CRIP1 and S100P in prostate cancer. Oncogene 26: 6560-6565, 2007.

35. Yu JM, Jun ES, Jung JS, Suh SY, Han JY, Kim JY, Kim KW and Jung JS: Role of Wnt5a in the proliferation of human glioblastoma cells. Cancer Lett 257: 172-181, 2007.

36. Torres MA, Yang-Snyder JA, Purcell SM, DeMarais AA, McGrew LL and Moon RT: Activities of the Wnt-1 class of secreted signaling factors are antagonized by the Wnt-5A class and by a dominant negative cadherin in early Xenopus development. J Cell Biol 133: 1123-1137, 1996.

37. Olson DJ and Gibo DM: Antisense wnt-5a mimics wnt-1-mediated C57MG mammary epithelial cell transformation. Exp Cell Res 241: 134-141, 1998.

38. Ishitani T, Kishida S, Hyodo-Miura J, Ueno N, Yasuda J, Waterman M, Shibuya H, Moon RT, Ninomiya-Tsuji J and Matsumoto K: The TAK1-NLK mitogen-activated protein kinase cascade functions in the Wnt-5a/Ca(2+) pathway to antagonize Wnt/beta-catenin signaling. Mol Cell Biol 23: 131-139, 2003.

39. Topol L, Jiang X, Choi H, Garrett-Beal L, Carolan PJ and Yang Y: Wnt-5a inhibits the canonical Wnt pathway by promoting GSK-3-independent beta-catenin degradation. J Cell Biol 162: 899-908, 2003.

40. Nemeth MJ, Topol L, Anderson SM, Yang Y and Bodine DM: Wnt5a inhibits canonical Wnt signaling in hematopoietic stem cells and enhances repopulation. Proc Natl Acad Sci USA 104: 15436-15441, 2007.
41. Yuzugullu H, Benhaj K, Ozturk N, Senturk S, Celik E, Toylu A, Tasdemir N, Yilmaz M, Erdal E, Akcali KC, et al: Canonical Wnt signaling is antagonized by noncanonical Wnt5a in hepatocellular carcinoma cells. Mol Cancer 8: 90, 2009.

42. Pourreyron C, Reilly L, Proby C, Panteleyev A, Fleming C, McLean K, South AP and Foerster J: Wnt5a is strongly expressed at the leading edge in non-melanoma skin cancer, forming active gradients, while canonical Wnt signalling is repressed. PLoS One 7: e31827, 2012.

43. Gujral TS, Chan M, Peshkin L, Sorger PK, Kirschner MW and MacBeath G: A noncanonical Frizzled2 pathway regulates epithelial-mesenchymal transition and metastasis. Cell 159: 844-856, 2014.

44. Yu M, Ting DT, Stott SL, Wittner BS, Ozsolak F, Paul S, Ciciliano JC, Smas ME, Winokur D, Gilman AJ, et al: RNA sequencing of pancreatic circulating tumour cells implicates WNT signalling in metastasis. Nature 487: 510-513, 2012

45. Miyamoto DT, Zheng Y, Wittner BS, Lee RJ3, Zhu H, Broderick KT, Desai R, Fox DB, Brannigan BW, Trautwein J, et al: RNA-Seq of single prostate CTCs implicates noncanonical Wnt signaling in antiandrogen resistance. Science 349: 1351-1356, 2015.

46. Zhan T, Rindtorff $\mathrm{N}$ and Boutros $\mathrm{M}$ : Wnt signaling in cancer. Oncogene 36: 1461-1473, 2017.

47. Yano H, Hara A, Shinoda J, Takenaka K, Yoshimi N, Mori H and Sakai N: Immunohistochemical analysis of beta-catenin in N-ethyl-N-nitrosourea-induced rat gliomas: Implications in regulation of angiogenesis. Neurol Res 22: 527-532, 2000.

48. Wang $Z$ and Chen $Q$ : $\beta$-catenin knockdown inhibits the proliferation of human glioma cells in vitro and in vivo. Exp Ther Med 11: 1059-1064, 2016.

49. Rossi M, Magnoni L, Miracco C, Mori E, Tosi P, Pirtoli L, Tini P, Oliveri G, Cosci E and Bakker A: $\beta$-catenin and Gli1 are prognostic markers in glioblastoma. Cancer Biol Ther 11: 753-761, 2011. 